\title{
The effects of rhythm changes on function and the ejection fraction of the left ventricle: the need for their conversion
}

\author{
Fatmir Ferati* \\ University Hospital Tetovo, Tetovo, Republic of Macedonia
}

The purpose of the study is the analysis of the effects of rhythm changes on the ejection fraction (EF) of the left ventricle (LV), which can be determined by echocardiography and other parameters like speckle tracking. ${ }^{1-4}$

We have analyzed hemodynamic changes and effect of conversion of the heart rhythm on the function of the heart. To have more realistic result we try to find the patient with spontaneously conversion of rhythm. For this purpose, we have analyzed five cases with different rhythm changes:

1. Patient with paroxysmal supraventricular tachycardia (PSVT) with the spontaneous rhythm conversion during the same control;

2. Patient with ventricular tachycardia (VT), converted with DC shock from an implantable cardioverter-defibrillator. Conversion was during the same control;

3. Patient with left bundle branch block (LBBB), with spontaneous withdrawn during the same control;

4. Patient with chronic atrial fibrillation (AF), with normal coronary angiography, which after several months converted spontaneously to sinus rhythm;

5. Patient with paroxysmal AF converted with amiodarone in a few day therapy.

The patients were analyzed through Tomtec Gmb software for 2D strain and for 4D strain.

While analyzing the hemodynamic effect of the heart rhythm, the need and the urgency for converting some of these rhythm changes in obvious, based on the effects that rhythm changes are in the hemodynamic function of the heart, represented by EF.

According to the data ${ }^{5}$, some of hemodynamic changes of the LV are almost minimal, like in patient with PSVT, while the changes are enhanced in the patients with AF, with an uncontrolled ventricular rhythm, and especially in the patient with VT. This shows the need for a fast conversion of the rhythm in ventricular tachycardia and with a DC shock when needed. Also in the patient with AF, in cases of inability for conversion of the rhythm in a sinus rhythm, control of the heart frequency, gives an important hemodynamic effect that can be seen from echocardiographic parameters.

KEYWORDS: paroxysmal supraventricular tachycardia, atrial fibrillation, left bundle branch block, ventricular tachycardia, echocardiography.

\section{Literature}

1. Paulus WJ, Tschope C, Sanderson JE, Rusconi C, Flachskampf FA, Rademakers FE, et al. How to diagnose diastolic heart failure: a consensus statement on the diagnosis of heart failure with normal left ventricular ejection fraction by the Heart Failure and Echocardiography Associations of the European Society of Cardiology. Eur Heart J. 2007;28:253950.

2. Leite-Moreira AF, Correia-Pinto J, Gillebert TC. Afterload induced changes in myocardial relaxation: a mechanism for diastolic dysfunction. Cardiovasc Res. 1999;43:344-53. 3. Natale A, Zimerman L, Tomassoni G, Kearney M, Kent V, Brandon MJ, et al. Impact on ventricular function and quality of life of transcatheter ablation of the atrioventricular junction in chronic atrial fibrillation with a normal ventricular response. Am J Cardiol. 1996;78:1431-3.

4. Khan HH, Maisel WH, Ho C, Suzuki M, Soejima K, Solomon S, et al. Effect of radiofrequency catheter ablation of ventricular tachycardia on left ventricular function in patients with prior myocardial infarction. J Interv Card Electrophysiol. 2002;7(3):243-7.

5. Ferati F. Rhythm changes and the function of the left ventricle: analysis of effects on the left ventricular ejection fraction. Cardiol Croat. 2013;8(3-4):88-96. 